\title{
OAXACA: NOTICIAS DE ARTISTAS 1680-1780
}

\author{
POR \\ FÁTIMA HALCÓN \\ Universidad de Sevilla
}

\begin{abstract}
The eighteenth century had a special relevance in the city of Oaxaca. The economic bloom due to diverse factors resulted in the appearance of a high social class that was interested in the artistic patronage. On the other hand the high religious hierarchy impelled diverse artistic works as much in the city as in the state giving an enormous palpable activity as a result in the new constructions that were carried out along the century. As consequence of everything had it an affluence of artists that worked in the city and a great visible artistic dynamism in all the manifestations of the art. The present article analyzes the details of the artists that began in Oaxaca, so much from its work and social perspective ace of the novelties that introduced inside the arts.
\end{abstract}

La ciudad de Oaxaca tuvo una imparable actividad artística desde el momento de la conquista. La necesidad más acuciante de los conquistadores fue dotar a las poblaciones anexionadas a la Corona española de una infraestructura acorde con las nuevas jerarquías establecidas. De este modo se construyeron catedrales y casas consistoriales, palacios de virreyes y mandatarios, conventos para albergar a los religiosos y hospitales para la población, todo planificado según la nueva ordenación urbanística implantada tras la caída de Tenochtitlán. Una vez superada esta primera fase, la actividad artística creció o se estacionó según las características específicas de cada ciudad y, en la mayor parte de los casos, estuvo relacionada con la Iglesia. Las órdenes religiosas aumentaron conforme se asentó la conquista. La llegada de nuevos religiosos supuso la construcción de edificaciones que rivalizaron con las ya existentes. A lo largo del siglo XVI arribaron a Nueva España provenientes de la metrópoli artistas que, atraídos por las posibilidades de trabajo, venían a desarrollar su oficio con la idea de «hacer las Américas». En algunos casos los propios frailes se encargaron de proyectar sus conventos siguiendo los modelos existentes en España, pero en otros, la traza se debió a artistas venidos ex profeso o, a partir de la segunda mitad del quinientos, nacidos en territorio novohispano. A finales del siglo XVI, las ciudades contaban con una configuración urbana estructurada en torno a una plaza principal donde tenían cabida los principales edificios, y siguiendo una planimetría ortogonal, las calles albergaban los distintos conventos, hospitales y casas, dándoles un aspecto armonioso y compacto.

Oaxaca siguió las mismas pautas. En los primeros años del quinientos se levantó la Cate- 
dral, los conventos de dominicos, franciscanos, mercedarios y jesuitas ${ }^{1}$. Se construyeron las Casas Consistoriales y las de los principales mandatarios - la casa de Cortés, por ejemplo- de forma que, a pesar de no disfrutar de una infraestructura adecuada a sus necesidades, como se recoge en muchos documentos, afloraba como una ciudad relevante, cabeza del estado del mismo nombre ${ }^{2}$. Las características telúricas de la zona, con graves temblores que la sacuden frecuentemente, tuvieron una importancia decisiva en la continuidad de la actividad constructiva, que prosiguió sin cesar hasta finales del setecientos. Podría afirmarse que Oaxaca es una ciudad en continuo devenir y así un edificio finalizado queda destruído por un fuerte temblor planteándose, de inmediato, su reconstrucción y, a veces, su cambio estético, una vez superada la catástrofe.

En las postrimerías del siglo XVII concurrieron una serie de circunstancias que motivaron una amplia actividad artística duradera hasta finales del siguiente siglo. En primer lugar, el gran auge económico desplegado en toda la zona debido al comercio de la grana. El padre Gay afirma que en aquel tiempo la ciudad de Oaxaca «disfrutaba de un envidiable bienestar ${ }^{3}$. El enriquecimiento económico favoreció la aparición de mecenas que, con su ayuda desinteresada, impulsaron nuevas construcciones, sobre todo religiosas, finalizándose, además, la ornamentación interior de muchas iglesias. Bajo el mecenazgo de Pedro de Otálora Carbajal se construye la iglesia de la Soledad entre 1682 y 1690. Otro mecenas, Manuel Fernández Fiallo, pagó numerosas obras en los conventos de carmelitas, agustinos, franciscanos, mercedarios, fundación de San Juan de Dios así como obras de carácter civil tales como fuentes públicas, reedificación de las Casas Consistoriales, carnicerías y acueducto para la conducción de las aguas. Aunque su muerte acaeció en 1708 muchas de las obras del primer cuarto del siglo XVIII se debieron a su patronazgo. Además de estos destacados mecenas, hubo muchas personas que dejaron parte de su patrimonio personal colaborando en el embellecimiento de la ciudad y en ayuda de las necesidades más apremiantes.

La Iglesia fue otro estamento que, con su mecenazgo, incitó y favoreció las obras artísticas emprendidas. En este sentido el papel que desempeñaron los obispos fue decisivo al tomar la iniciativa de la mayor parte de las obras religiosas que, en muchos casos, fueron financiadas por ellos mismos. En los últimos años del siglo XVII fue obispo D. Isidoro Sariñana; bajo su mandato se construyó la iglesia de la Soledad, se fundó un colegio para la formación de jóvenes y se repararon numerosas iglesias y conventos. En los comienzos del XvIII, el obispo Fr. Ángel Maldonado, de la Orden de San Bernardo, reconstruyó la Catedral, dañada gravemente tras los terremotos de 1696 y 1702, remodelando y afianzando sus bóvedas y añadiéndole la capilla de Guadalupe. Reedificó, bajo su propio patrocinio, el Colegio de los Jesuítas, dañado igualmente por los temblores. Su sucesor, Fr. Francisco Santiago Calderón, mercedario, prosiguió la reconstrucción de la Catedral, añadiéndole las dos torres de la fachada; comenzó las obras de la iglesia de San Felipe Neri y las del convento de las capuchinas de San José. Hacia mediados de siglo cabe destacar la figura del obispo D. Diego Felipe Angulo que amplió el Hospital de San Cosme y San Damián y la de D. Miguel Anselmo Alvarez de Abreu, familiar quizás del obispo de Puebla de los Ágeles D. Panteleón Alvarez de Abreu —de origen canario-, quién reparó la iglesia de las Nieves destruída casi en su totalidad por los terremotos ${ }^{4}$. En muchas de estas

\footnotetext{
${ }^{1}$ Burgoa, Francisco de: Geográfica Descripción de la parte septentrional de la América..., 2 volúmenes. México, 1934.

2 AGI. México, 210, n. ${ }^{\circ} 22$. En una carta del regidor de la ciudad D. Gaspar de Vargas, fecha 17 de febrero de 1569 , al Presidente de la Real Audiencia le expone sus quejas sobre las necesidades de la ciudad con respecto a fuentes, caminos, calzadas y puentes.

${ }^{3}$ Gay, José Antonio: Historia de Oaxaca. Editorial Porrúa. Tercera edición. México, 1990. p. 320

${ }^{4}$ Ver: Canterla Martín, Francisco: La iglesia de Oaxaca en el siglo XVIII. Escuela de Estudios Hispanoamericanos. Sevilla, 1982
} 
obras, los obispos no sólo incitaron el proyecto sino que, en muchos casos, gastaron grandes sumas de dinero de su propio pecunio para poder solventar los gastos que se iban ocasionando.

El factor económico, debido al comercio, el religioso, por el afán de obispos y priores y el sismológico, con la destrucción y reconstrucción de los edificios y sus enseres, fueron decisivos para establecer un análisis de lo que supuso la actividad artística que se desarrolló en la ciudad durante esta época. Las obras emprendidas abarcaron todas las ramas del conocimiento artístico, destacando un buen número de artistas locales que dejaron su impronta en obras arquitectónicas, retablísticas y pictóricas. Desde la edificación de la iglesia de la Soledad, comenzada en 1682 y cuya extraordinaria y novedosa fachada rompe la hegemonía de las fachadas oaxaqueñas, hasta las últimas grandes obras realizadas en el último cuarto del siglo XVIII, el convento de los Siete Príncipes y la reconstrucción del convento de San Francisco, se puede establecer una cronología de los edificios religiosos más representativos de la ciudad que se levantaron de nueva planta o se reconstruyeron en estos años: La iglesia de la Soledad, el convento de la Merced, la fachada del convento de San Agustín, el convento del Carmen Alto, la capilla del Rosario de los dominicos, la reconstrucción y terminación de la Catedral, la remodelación de la iglesia de la Compañía, el convento de las Capuchinas de San José, la iglesia de San Felipe Neri, el convento de los Siete Príncipes y el de San Francisco. A ello cabe añadir las obras de carácter civil, oficial y doméstico, que sin tener la envergadura de las de carácter religioso merecen nuestra atención por cuanto dotaron a la ciudad de un paisaje urbano peculiar así como de una infraestructura necesaria.

Los artistas que trabajan en Oaxaca durante este período fueron en su mayoría locales, salvo algún caso aislado de artistas venidos de Puebla o de México. La ciudad de los Ángeles se consideró, bien por su cercanía o por su calidad artística, un punto de referencia obligado a la hora de plantearse una nueva obra, demandándose la presencia de artistas poblanos en los nuevos proyectos. Este hecho es apreciable cuando se trata de obras o edificaciones religiosas, particularmente del templo catedralicio ${ }^{5}$. Hubo un número considerable de artistas de origen español o venidos de otros lugares de México que atraídos por la pujanza económica de la ciudad dirigieron algunas de las obras más representativas, tal es el caso de Tomás de Sigüenza o Felipe de Ureña. No cabe duda que a ellos se les debe, en buena parte, un cambio de las formas artísticas de la ciudad en un determinado momento.

Carecemos de datos concretos que nos den una idea cierta de la formación que tuvieron estos profesionales. No hemos hallado inventarios de bibliotecas ni testamentos que acrediten sus conocimientos teóricos y, salvo el caso de Felipe de Ureña, que llega a la ciudad con una bagaje artístico avalado por sus numerosas obras en otros lugares de la nación, resulta difícil valorar sus conocimientos y experiencia. Posiblementente, los artistas locales sacarían modelos de las estampas que circularían por los talleres. La extensa biblioteca del convento de Santo Domingo también pudo contribuir al saber de los artistas. La existencia de determinados libros que se encontraban en ella pudieron servir de base en algunos obras, particularmente el de Juan de Torixa y el de Diego López de Arenas ${ }^{6}$. El primero, editado en Madrid en 1661 y que trata la forma

\footnotetext{
5 Algunos documentos encontrados aluden este hecho. El maestro platero Miguel Olaechea viene en 1703 de Puebla de los Ángeles para trabajar en la Catedral donde realiza seis blandones y seis jarras con sus ramilletes (ACO. Libro de Clavería. Año 1703, p. 27 v.); en 1706 vuelve de nuevo para hacer la lámpara grande de la Catedral (ACO. Libro de Clavería. Año 1706, p. 27 v.) y un año más tarde hace dos incenciarios, una peana y una cruz de mano decorada con plata dorada (ACO. Libro de Clavería. Año 1707). El maestro bordador Juan Matheo Gomez de Valle viene de Puebla de los Ángeles en 1703 para trabajar en la Catedral donde hace una serie de ornamentos (AGNEO. Protocolo Diego Benaias. Año 1703, 18 de agosto); En 1707, vuelve a trabajar para la Compañía de Jesús realizando unos ornamentos de oro como los que había hecho para el convento de Santa Catalina (AGNEO. Protocolo Diego Benaias, p. 154).

${ }^{6}$ Ver: Grañén Porrúa, M. ${ }^{\mathrm{a}}$ Isabel y otros: Las joyas bibliográficas de la Universidad Autónoma «Benito Juárez» de Oaxaca. Fomento Cultural Banamex, México, 1996.
} 
de construir «con sigularidad y modo moderno» los embovedamientos, debió utilizarse como modelo de las bóvedas catedralicias, levantadas de cantería entre 1667-1682, y de las restantes iglesias construídas en los últimos años del siglo XVII ${ }^{7}$. Con respecto al segundo, editado en Sevilla en 1727, fue, al menos en el ámbito sevillano, punto de referencia constante entre arquitectos y retablistas. Otra modalidad en los planteamientos de obras nuevas fue la copia de las ya realizadas por otro artista en el mismo lugar. Este hecho es apreciable cuando se trata de retablos en los que se obliga a copiar otros existentes, tanto en la traza como en la decoración ${ }^{8}$.

El centro generador de la actividad artística lo constituyeron los talleres. Allí se realizaban las obras que, posteriormente, serían colocadas en sus respectivos espacios. En general, los artistas prefirieron trabajar en su taller y únicamente aceptan trabajar en el lugar donde vaya a instalarse la obra cuando es requisito indispensable en el contrato. Cuando se trata de obras en poblaciones periféricas, generalmente, se exige a los artífices instalar los talleres en el propio emplazamiento pero también se dieron casos de obras de gran envergadura dentro de la propia ciudad en las cuales se les obliga, mediante contrato, a esteblacerse en el lugar de la obra. Tal es el caso de Blas de los Ángeles mientras realiza un retablo para la iglesia de Etla y de Tomás de Sigüenza mientras trabaja para el convento de San Francisco de Oaxaca ${ }^{9}$. Hubo talleres de retablistas y de pintores, organizados jerárquicamente con maestros, oficiales y aprendices. Los maestros contrataban aprendices de edad comprendida entre los once y los dieciocho años y se obligaban a enseñarles el oficio y mantenerlos durante el tiempo —entre dos y seis años-que durase su formación. El período analizado ofrece mayor cantidad de contratos de aprendices de retablistas y pintores que arquitectos. Hay que tener en cuenta que existió una gran actividad retablística cuya estructura se adornaba, generalmente, con lienzos y que por lo tanto estos talleres tendrían mayor movimiento de artistas ${ }^{10}$.

El contrato fue el instrumento del que se valieron artistas y comitentes para la obligación de las obras. Se firmaban ante notario constituyendo una garantía para ambas partes en las eventualidades que pudiesen ocurrir durante el transcurso de su cumplimiento. Los contratos espe-

\footnotetext{
${ }^{7}$ Mulle, Robert J.: La arquitectura y escultura de Oaxaca 1530-1980. Volumen I. La ciudad de Oaxaca. Codex Editores. México, 1992, pp. 12 y ss.

${ }^{8}$ Tomás de Sigüenza contrata en 1693 un retablo dedicado a San Miguel para la iglesia de la Compañía de Jesús que debe hacer según «la traza del retablo de Ntra. Sra. de la Concepción que esta en la misma iglesia» (AGNEO. Protocolo Diego Benaias. Año 1693, 6 de febrero). Andrés de Zárate, maestro entallador, contrata en 1709 la realización de un retablo para el Cristo de la iglesia de Tlacolula «asemexando a lo que en el primer cuerpo que hizo en el retablo del S. Xpto.» del pueblo de Huayapan (AGNEO. Protocolo Diego Romero. Año 1708-1710, 19 de enero de 1709). Lázaro y Francisco Canseco, padre e hijo, maestros de carpintería contratan hacer un retablo para la iglesia del pueblo de San Pedro «en la forma y manera que está otro en la propia iglesia» (AGNEO. Protocolo Manuel Franco de Lara. Año 1774, p. 302).

${ }^{9}$ Blas de los Ángeles, maestro ensamblador, contrata en 1684, tallar y dorar un retablo para la iglesia de Etla en el plazo de un año que debe realizarlo entero en dicha ciudad «sin poder salir de ella hasta haber acabado la obra» (AGNEO. Protocolo de Francisco de Quero. Año 1684, 7 de marzo). Tomás de Sigüenza contrata en 1689 hacer el retablo mayor y el sagrario de la iglesia del convento de San Francisco en el plazo de seis meses poniendo materiales y oficiales debiendo trabajar dentro del convento «sin entrometer otra obra alguna» (AGNEO. Protocolo Francisco de Quero. Año 1689, 13 de abril).

${ }^{10}$ Pedro Calderón, maestro pintor, contrata como aprendiz a Domingo Muñoz, hijo natural de Antonio de Paz, de dieciocho años por dos años (AGNEO. Protocolo Francisco de Quero. Año 1689, 4 de agosto).

Agustín Mendez, maestro pintor, contrata como aprendiz durante tres años aIsidro de Castro, de once años (AGNEO Protocolo Francisco de Quero. Año 1688, 23 de abril); en 1700 contrata a Felipe de la Cueva, de trece años, durante seis años (AGNEO. Protocolo Diego Benaias. Año 1700, 25 de mayo).

Lorenzo Tiburcio de León, maestro pintor, contrata como aprendiz a Mariano Canseco, de quince años, durante dos años (AGNEO. Protocolo Manuel Franco de Lara. Año 1768, 16 de agosto).

Andrés de Mijangos, maestro entallador y ensamblador, contrata como aprendiz a José Eugenio Sanchez (AGNEO. Protocolo José Alvarez Aragón. Año 1702, 27 abril).

Joseph Ramírez, maestro entallador y carpintero, contrata como aprendiz a Marcial Gutierrez de catorce años durante cinco años (AGNEO. Protocolo Francisco de Quero. Año 1688, 3 de febrero).
} 

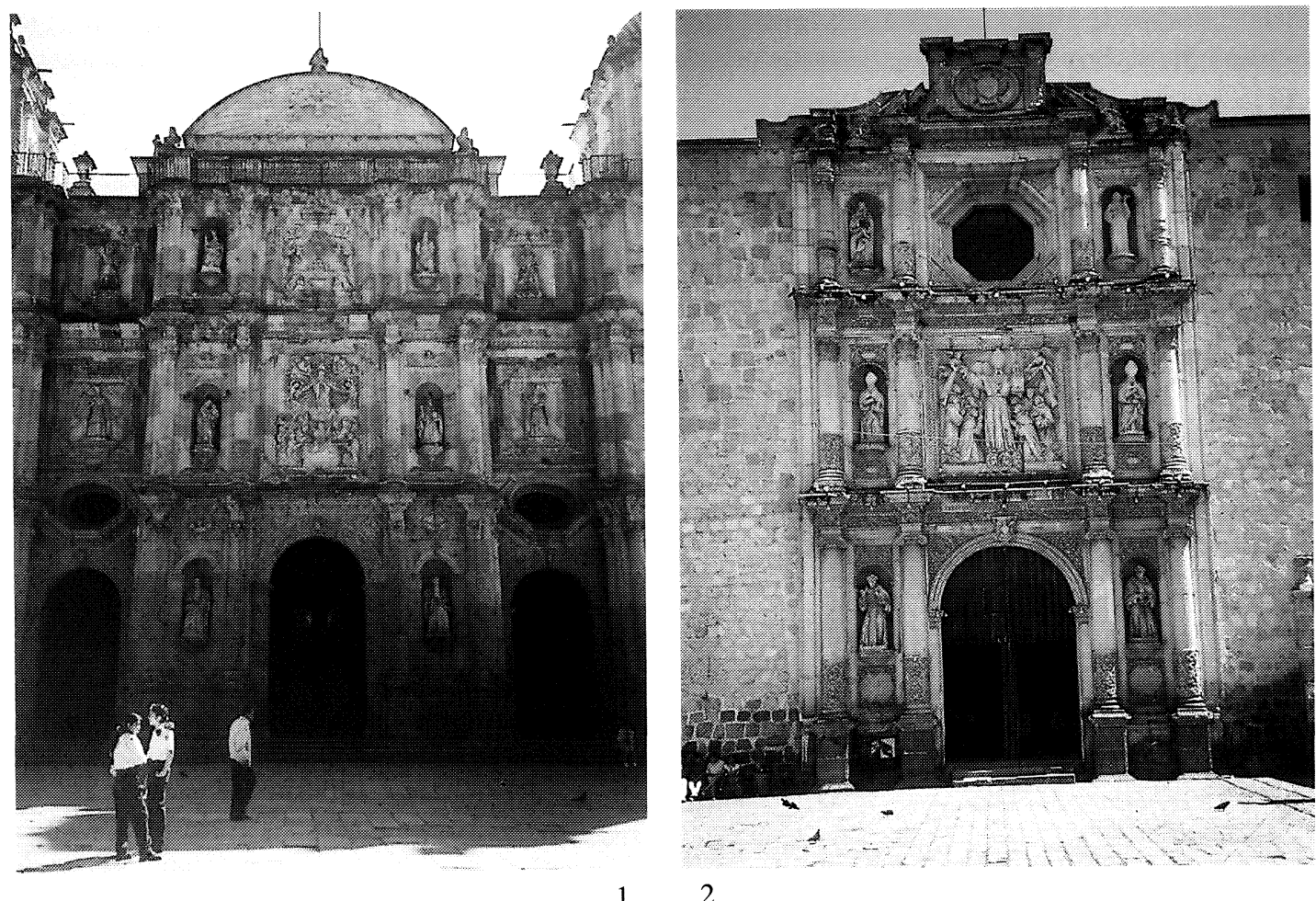

3

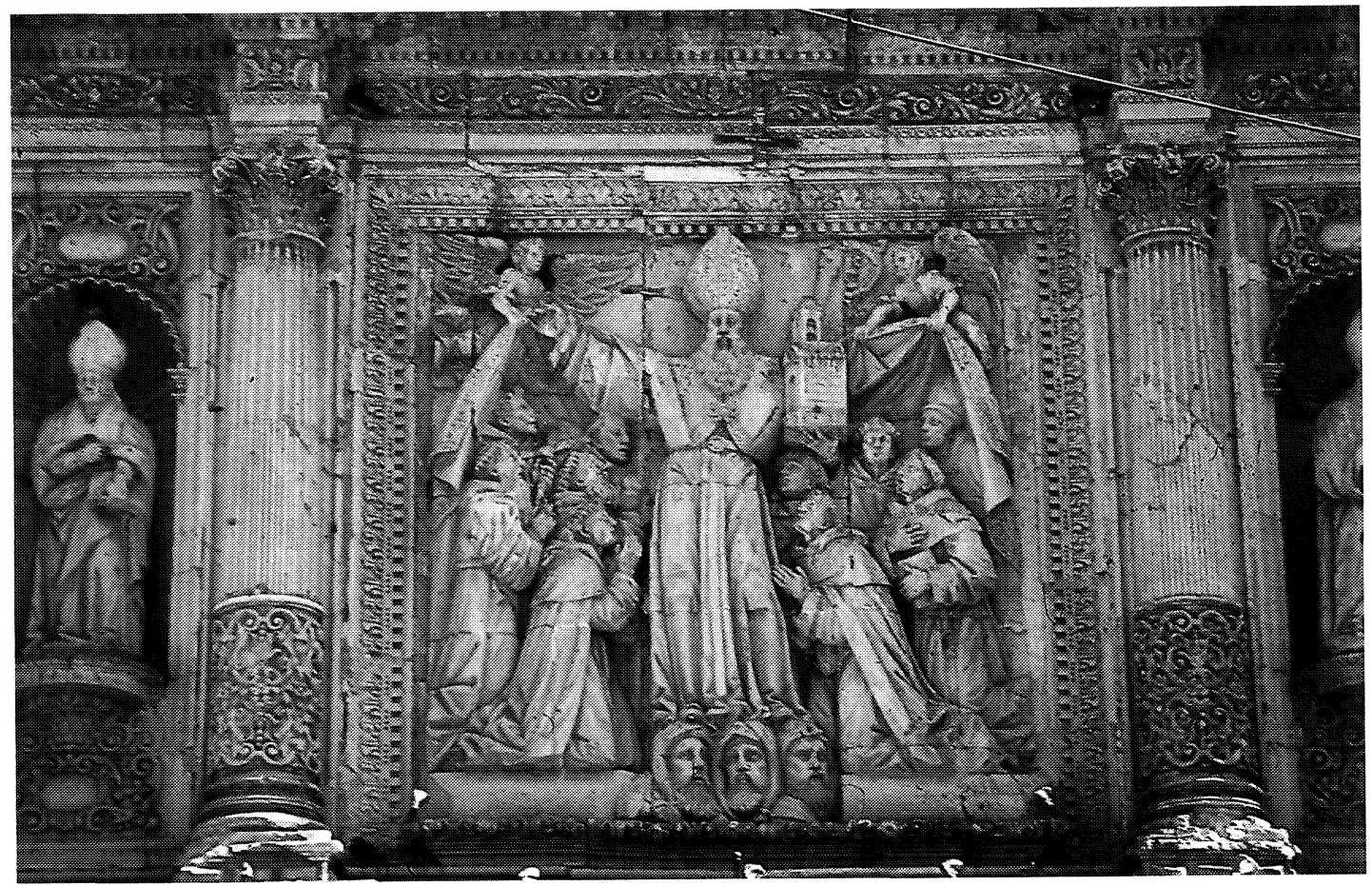

Fig. 1. Fachada principal. Oaxaca. Catedral.

Figs. 2 y 3. Tomás de Sigüenza. Fachada principal y detalle. Oaxaca. Iglesia de San Agustín. 
cificaban los aspectos constructivos, ornamentales y, en su caso, iconográficos de cada obra, estableciendo el tipo de piedra o madera que debía usarse. Además se establecían los plazos de ejecución y la forma de pago. Por lo general, se pagó en pesos pero hubo algunos ejemplos de pagos en especie. A Blas de los Ángeles se le pagan dos mil quinientos pesos por la traza y hechura del retablo de la iglesia de Etla y «cuatro fanegas de maíz, un carnero, un vestido de paño de Castilla y un indio para el acarreo de leña y agua» ${ }^{11}$. No siempre se cumplieron los contratos con la exactitud de su descripción y algunos artistas se ven obligados a dejar la obra por falta de pago. Alfonso de Pinos se obliga a hacer un retablo para la iglesia de San José de Oaxaca «no terminado por no haberle terminado de pagar» ${ }^{12}$. En los contratos de obras de mayor relevancia existieron avalistas que debían responder ante el contratante para subsanar los daños en caso de incumplimiento, bien continuando las obras o reintegrando las cantidades cobradas.

La posición económica de los artistas fue muy variable aunque en general puede afirmarse que no poseyeron unas condiciones de vida favorables. Su nivel económico dependía de los ingresos proporcionados por su oficio siendo muy irregular los períodos de trabajo constante. Existe una diferencia con respecto a los pagos en razón a la envergadura de la obra y de la categoría como artista. También se aprecian mayores pagos en la ciudad de Oaxaca que en poblaciones periféricas. Los maestros más destacados tuvieron casa en propiedad, caso de Tomás de Sigüenza, arquitecto y retablista, que vivía en una casa propia en el barrio de San Francisco, frente a la huerta del convento ${ }^{13}$; Miguel de Sanabria, maestro de arquitectura, que compra una casa al convento de Regina Angelorum en el barrio de la Merced ${ }^{14}$; Jerónimo de Pinos, maestro ensamblador, quién también poseyó otra casa en el mismo barrio ${ }^{15}$. Pero la mayoría de los artistas tratados vivieron en casas arrendadas por carecer de los medios económicos suficientes para comprarlas en propiedad.

Dentro del período que analizamos hubo artistas que destacaron bien por la cantidad y calidad de sus obras bien por introducir nuevos léxicos artísticos en la ciudad. El caso de Tomás de Sigüenza puede considerarse paradigmático. Este artista de origen español nació en $1662{ }^{16}$. Nada sabemos de su formación ni de las causas que le impulsaron a trasladarse a México y, posteriormente, a Oaxaca. En esta ciudad tuvo un papel relevante como arquitecto y retablista. En 1696 y bajo el patrocinio de D. Manuel Fernández Fiallo trazó y talló la fachada del convento de San Agustín imponiendo un modelo de fachada-retablo, compuesta de tres cuerpos, tres calles más remate; sus característicos y robustos marcos para los relieves se repetirían en muchas de las portadas oaxaqueñas posteriores. Siguiendo los órdenes clásicos en la articulación de la facha$\mathrm{da}$, utiliza un tipo de columna estriada y decorada en su tercio inferior con talla menuda que se copiará posteriormente en arquitectura y retablística ${ }^{17}$. Se le atribuye, asimismo, la fachada de la iglesia de la Soledad una de las más interesantes, desde el punto de vista arquitectónico, de la ciudad. Se trata de una fachada de planta quebrada, traducida en avances y retrocesos de las calles donde sus conocimientos de la retablística aparecen evidentes. La fachada, de marcada verticalidad, está compuesta de tres cuerpos y ático. En el segundo cuerpo utiliza el mismo tipo de columna que en el convento de San Agustín mientras que en el tercero introduce una modalidad de columna helicoidal con hojas de parra y decorada en su tercio inferior por una talla vegetal

11 AGNEO. Protocolo Francisco de Quero. Año 1684, 7 de marzo.

12 AGNEO. Protocolo José Álvarez Aragón. Año 1737, p. 168.

13 Halcón, Fátima: Noticias de Tomás de Sigüenza en Oaxaca» en Acervos. Instituto de Artes Gráficas de Oaxaca. Oaxaca, 1996, pp. 23 y ss.

${ }^{14}$ AGNEO. Protocolo Manuel Alvarez Aragón. Año 1727, 23 de enero). Miguel de Sanabria compra la casa por 420 pesos, obligándose a tenerla siempre «inhiesta y reparada de todo sin poderla dividir».

${ }^{15}$ AGNEO. Protocolo Diego Benaias. Año 1694, p. 548. Cuando compra la casa está casado con María de Verganza.

${ }^{16}$ Halcón, Fátima: Op.cit.

17 Hernández Díaz, Gilberto: El convento de San Agustín de Oaxaca. Edición Conmemorativa. Oaxaca, 1992. 
plana; se trata de una tipología que se repite en algunos de los retablos de esta época como los del convento de San Agustín o de la Merced ${ }^{18}$.

Si su labor como arquitecto fue destacada no lo fue menos como retablista. Sus trabajos para la iglesia del convento de San Francisco, La Compañía y la Catedral así lo acreditan. La mayor parte de sus retablos siguen la tipología de las fachadas - dos cuerpos y ático— aunque utiliza otros elementos de soporte. En 1689, contrató el retablo mayor de la iglesia de San Francisco en el cual hace la traza, la talla y el dorado, obligándose a poner los materiales y los oficiales, a vivir en el convento durante la realización de la obra y a finalizarlo en seis meses, cobrando por todo doscientos cuarenta pesos. El retablo debía llevar ocho columnas salomónicas para formar las entrecalles donde se disponían cuatro esculturas empotradas en sus correspondientes nichos y otras dos en el ático para enmarcar el relieve. Estas columnas salomónicas debieron ser las primeras que se utilizaron en la ciudad de Oaxaca durante el barroco, no existiendo ejemplos anteriores a esta fecha ni en arquitectura ni en retablos. Diferentes características tipológicas se aprecian en el retablo lateral dedicado a la Virgen del Rosario del citado convento que contrata 1696 junto a Manuel Rodríguez, maestro ensamblador y entallador. El retablo se centraba por un hornacina con la imagen de la Virgen entre cuatro columnas, dos a cada lado. El segundo cuerpo y el ático quedaban centralizados por sendos lienzos representando la Asunción de la Virgen y la Trinidad, respectivamente. La Asunción de la Virgen estaba flanqueada por dos columnas y dos arbotantes mientras que la Trinidad se colocaba en una tarja sin columnas.

Para la iglesia la Compañía de Jesús contrató en 1696 un retablo lateral dedicado a San Miguel. En el contrato se puntualiza que debía copiar otro existente en la misma iglesia, el dedicado a la Inmaculada Concepción. Se trataba de un retablo compuesto por tres cuerpos y ático obligándose a poner las maderas y el oro, cobrando por su trabajo mil trescientos pesos. Comienza a trabajar para la Catedral a partir de 1700 en trabajos de carpintería tales como hechura de puertas, tarimas, peanas y banquillos. Un año más tade se le encarga el Monumento para las prácticas litúrgicas de la Semana Santa que debía realizarlo en blanco pues el dorado se concertó con el maestro Aragonés en mil trescientos pesos. La traza que presentó al Cabildo estaba articulada mediante tres cuerpos, ajustando su precio en mil doscientos pesos. Durante los años siguientes trabajó constantemente para el Cabildo Catedralicio realizando el armazón de madera para el sagrario de plata que hace el maestro platero Thomas de Herrera destinado al altar mayor ${ }^{19}$, diversos armarios para la sacristía y en la colocación del Monumento de la Semana Santa. Su encargo más destacado lo tuvo en 1708 concertando el aderezo y dorado del altar mayor de la sede metropolitana en mil seiscientos diecisiete pesos. Trabajó tres años más para el Cabildo en obras de menor enjundia y a partir de 1712 no se han encontrado más noticias suyas en la ciudad. Sin embargo, se tiene constancia de su presencia en la ciudad de México en 1730 donde figura como testigo en la pretensión de grados de doctor en Teología de D. Manuel José de Veitia. En su declaración atestigua ser vecino de la ciudad de México, ser natural de los reinos de Castilla y tener sesenta y ocho años. Desconocemos los motivos que le impulsaron a abandonar Oaxaca pero debieron ser fundamentados por el prestigio y categoría que gozaba como artista. No existe constancia de hijos suyos que siguieran con la tradición del oficio familiar si bien Heinrich Berlin realciona con Tomás de Sigüenza a unos escultores oaxaqueños del mismo apellido que trabajaron en Guatemala durante la segunda mitad del siglo XVIII ${ }^{20}$.

${ }^{18}$ Castañeda Guzmán, Luis: «Fray Sebastián de San Felipe, el arquitecto del convento de Nuestra Señora de la Soledad» en Cuaderno de Oaxaca. Oaxaca, junio 1950, pp. 15 y ss. y Vargas Lugo, Elisa: Portadas religiosas de México. UNAM. México, 1969.

19 ACO. Libro de Clavería. Año 1704, p. 40.

${ }^{20}$ Berlin, Heinrich: Historia de la Imagninería Colonial en Guatemala. Ministerio de Educación Pública. Guatemala, 1952. 
Durante la primera mitad del siglo XVIII destaca otro artista de origen español: Alfonso de Pinos, maestro carpintero y dorador. Perteneciente a un taller familiar dedicado al arte de la carpintería y afincado en Oaxaca, fue hijo de Domingo de Pinos y de Dalmira Cortés ${ }^{21}$. Su hermano, Gerónimo de Pinos, fue ensamblador y como tal aparece en 1694 viviendo en una casa de su propiedad en el barrio del convento de la Merced. Siguiendo la tradición de relaciones familiares entre artistas, se casa por segunda vez en 1722 con María de Sigüenza, posiblemente hija de Tomás de Sigüenza. Estos lazos de parentesco, tan habituales en la metrópoli, se traspolaron a Nueva España donde también se puede constatar el establecimiento de relaciones familiares entre artistas $^{22}$. Como ocurre con otros artistas novohispanos, su labor no se circunscribe meramente a la carpintería pues figura como maestro carpintero, dorador y ensamblador. A partir de 1726, trabajó para el Cabildo catedralicio realizando trabajos de pequeña envergadura: puertas, tarimas, aparadores, muebles de sacristía, etc., encargándosele, asimismo, la composición de una imagen de la Virgen de la Asunción ${ }^{23}$. Esta imagen pudiera ser la que se encarga en 1721 a la ciudad de Puebla y por la que se pagaron doscientos cuarenta y nueve pesos ${ }^{24}$. En ese mismo año, el Cabildo Catedralicio encargó un retablo para el altar de los Reyes «en blanco» por el que paga mil ochocientos pesos. Aunque la documentación no aclara el nombre del maestro que lo realiza, Alfonso de Pinos intervendría directamente en él como veremos a continuación. El primer interrogante que plantea este encargo es si este altar de los Reyes correspondería al retablo mayor. La Catedral debía tener el retablo mayor que dora y adereza Tomás de Sigüenza en 1708. Cabría la posibilidad de que este retablo hubiese quedado gravemente dañado o destruido tras el terrible terremoto de 1714. Otra posiblidad es que el retablo de los Reyes estuviese en una de las naves del templo, hecho poco probable dado la importancia de su iconografía y el importe que se paga. Por estos años se están finalizando las obras arquitectónicas del templo catedralicio así como su fachada principal, por lo tanto, nos inclinamos a pensar que el Cabildo, queriendo emular el retablo de los Reyes de la Catedral de México proyectado por Jerónimo de Balbás en 1718, le encargase a Alfonso de Pinos la realización de un retablo semejante para la sede oaxaqueña. El retablo se comenzó en 1726 y se finalizó en 1734. Entre estos años cobra pequeñas cantidades por «la obra del retablo de los Reyes» y por el frontal del altar, finalizando los pagos en 1734 con el cobro de dos mil doscientos cuarenta y nueve pesos por dorarlo, especificando que el débito total al artista era de tres mil doscientos veintinueve pesos ${ }^{25}$. Dada la alta cifra que percibe pensamos que se le encargó la traza y el dorado. Realizó, igualmente, en 1731 el túmulo para las honras fúnebres de Benedicto XIII ${ }^{26}$. Durante los años que trabaja en el retablo de los Reyes se le encargan pequeños trabajos para la Catedral de los cuales destacamos las puertas para el órgano y los espejos grandes para la sacristía ${ }^{27}$. También intervino como retablista en otras iglesias de Oaxaca. Para la iglesia de San José concertó en 1733 un retablo dedicado al santo, retablo que después de cuatro años aún estaba sin finalizar por no habérsele pagado lo estipulado en el contrato. Cuatro años más tarde realizó dos retablos laterales para la nueva iglesia de Orden Tercera de San Francisco de los que desconocemos su iconografía y estructura ${ }^{28}$. Independientemente de sus trabajos

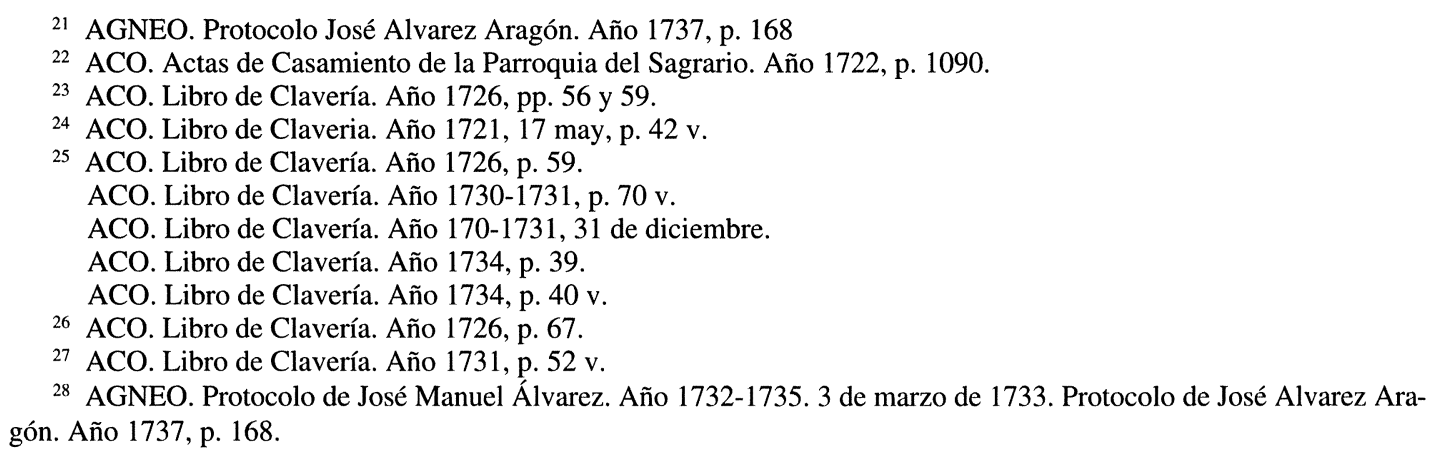


como retablista y dorador, Alfonso de Pinos aparece en varios inventarios valorando los bienes; como maestro carpintero valoró las obras de arquitectura que se realizaron en en las casas del mayorazgo de Ramírez de Aguilar ${ }^{29}$ y, junto al maestro platero Antonio Loaiza, los bienes de D. ${ }^{a}$ Rosa Hidalgo ${ }^{30}$.

La Catedral de Oaxaca monopolizó las obras más importantes de la ciudad. Desde su edificación trabajaron en ella los artistas más afamados y bien por iniciativa de los obispos, deseosos de tener una sede acorde con el lugar, bien por la necesidad imperante de reconstruir lo destruído por los temblores, la Catedral se constituyó en el espacio privilegiado donde arquitectos, escultores, carpinteros, pintores y plateros podían lucir sus sabiduría y conocimientos en aras de una ansiada fama. Este fue el caso de Miguel de Sanabria. Mestizo, nacido en Oaxaca, sabemos que se avencidaba en ella cuando contrae matrimonio por segunda vez en 1719 con Isabel del Castillo ${ }^{31}$. Fue el arquitecto más destacado de la ciudad en los primeros decenios del siglo XVIII. La primera gran obra que realiza fue la iglesia de Guamelulco que tuvo que levantar de nuevo desde sus cimientos ${ }^{32}$. La iglesia constaba de una sola nave abovedada, crucero con media naranja y linternilla, tres portadas, dos torres de un cuerpo - cada una con cuatro huecos para las campanas-, sacristía y capilla bautismal. Firma el contrato en 1703, realizando la traza y los dibujos de la portada principal, la media naranja y las torres y cobrando por toda la obra 3.500 pesos.

El grave terremoto ocurrido en la ciudad en 1714 destruyó gran parte de la Catedral motivando la intervención arquitectónica de Miguel de Sanabria desde 1724 a 1736 después de una larga diatriba como veremos a continuación. Uno de los arquitectos que trabajaba por entonces en la ciudad en obras de menor envergadura, Nicolás Sanchez, pretendió la dirección de las obras. Este arquitecto había restaurado la acometida de aguas de Oaxaca, reparando los principales arcos y las cañerías del acueducto ${ }^{33}$. Además, en 1708, trabajó para la Catedral en la reparación del cimborrio por lo que cobró seiscientos treinta y un pesos ${ }^{34}$. Sin embargo, el Cabildo, ante la desconfianza que le inspiraba este artífice, decide traer un arquitecto de México que no llegó por falta de medios económicos hasta 1723. Este arquitecto, Joseph Manuel de la Mata, redactó una relación de las obras que debían emprenderse que fueron rechazadas tras ser revisadas por los maestros capitalinos Miguel de Rivera y Pedro de Arrieta ${ }^{35}$. El proyecto de Joseph Manuel de la Mata hubiera implicado el gasto de una fortuna, de la cual no se disponía, aparte de la edificación de tres cimborrios más. En otoño de 1724 se reune de nuevo el cabildo catedralicio y determina que la dirección de las obras de la Catedral las llevase Miguel de Sanabria. La obra de la Catedral consistió, fundamentalmente, en reparar las bóvedas dañadas y fabricar de nuevo arcos y pilares. Asimismo, levantó la media naranja del crucero, reconstruyó las capillas laterales, algunas de ellas derribadas en gran parte, y levantó las torres desde sus cimientos. Las torres están decoradas únicamente en el cuerpo de campanas que presentan un vano flanqueado por dobles medias columnas estriadas helicoidales sobre las que descansa un entablamento de potente cornisa. Una cúpula con azulejos bicolores remata el conjunto. Durante los años que duró la obra debió gozar de una buena posición económica pues en 1727 se compra una casa como se ha citado ${ }^{36}$. En 1730, comparece como maestro mayor de la ciudad de Oaxa-

\footnotetext{
29 AGNEO. Protocolo José Manuel Álvarez Aragón. Año 1713, p. 97.

${ }^{30}$ AGNEO. Protocolo José Manuel Álvarez Aragón. Año 1732, 18 de abril.

31 ACO. Actas de Casamientos de la Parroquia del Sagrario. Año 1719, 15 de enero.

32 Berlin, Heinrich: «Oaxaca: San Felipe Neri. Noticias de artífices» en AEA. Madrid, 1983, pp. 47-63.

3 AGNEO. Protocolo Diego Benaias. Año 1686, pp. 3 y ss.

34 ACO. Libro de Clavería. Año 1708, p. 11.

35 Berlin, Heinrich: «Arquitectura y arquitectos coloniales de Oaxaca: La Catedral» en AEA. Madrid, 1979, pp. $307-328$.

36 Ver nota $n .^{\circ} 14$
} 
4

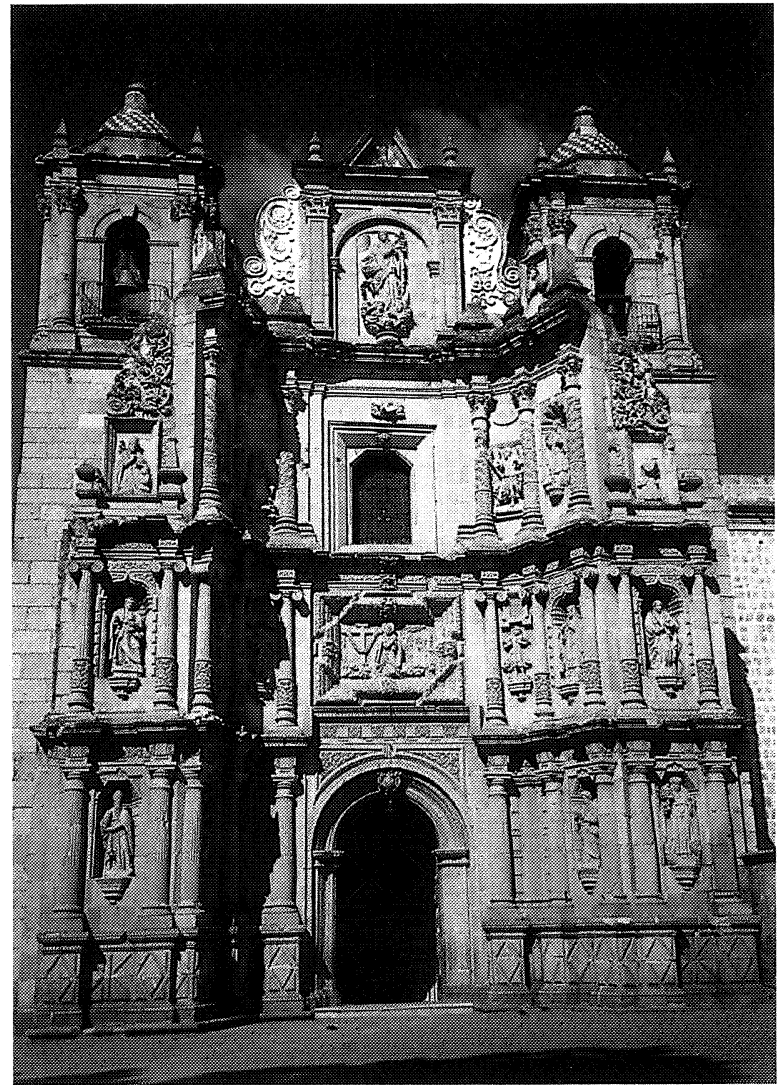

5
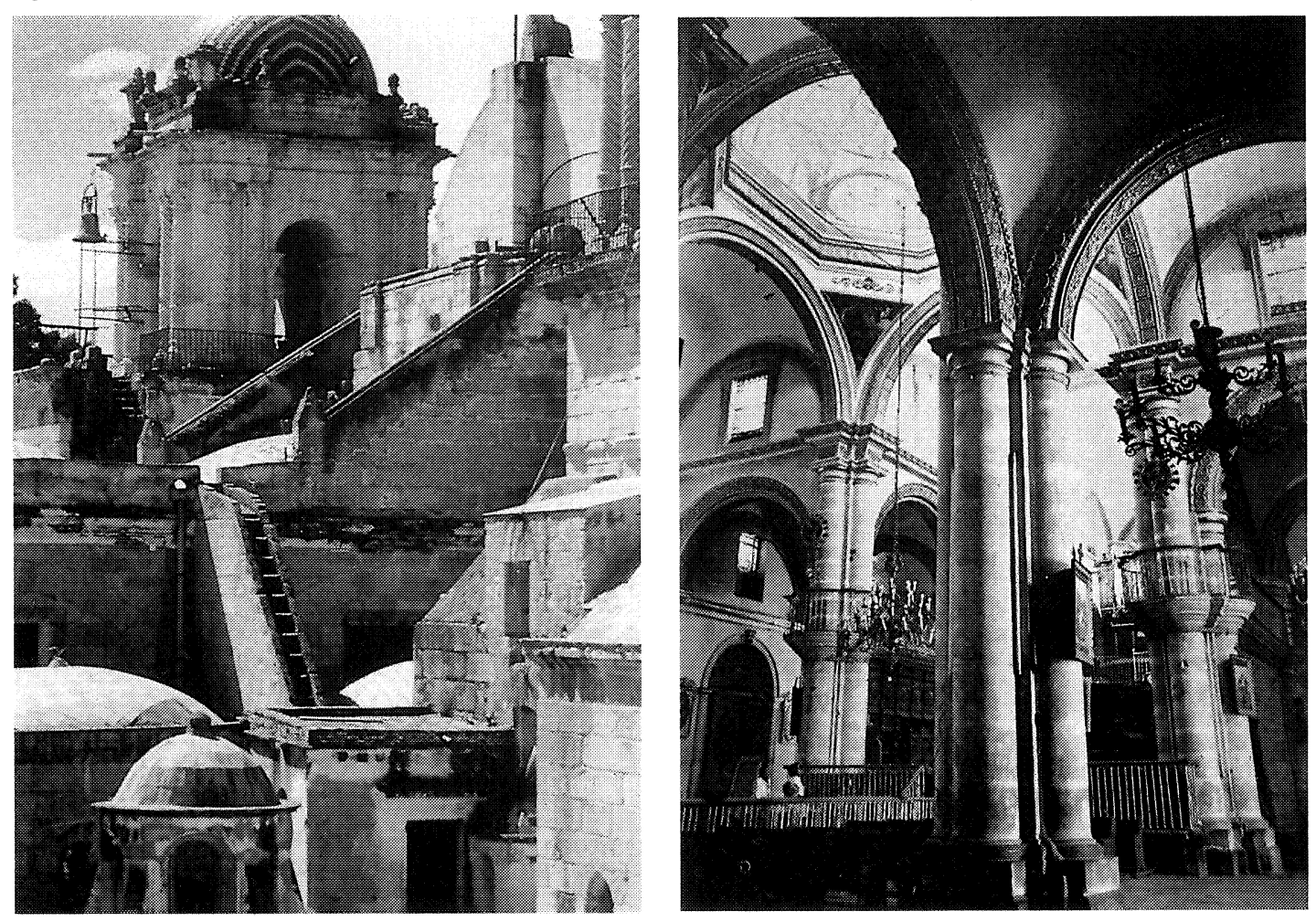

Fig. 4. Tomás de Siguienza (?). Fachada principal. Oaxaca. Iglesia de la Soledad. Figs. 5 y 6 . Miguel de Sanabria. Torres y Crucero. Catedral. 


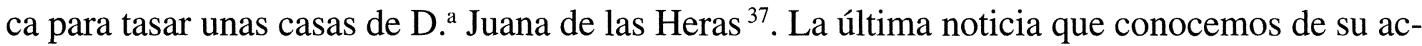
tividad fue la tasación de unas casas en 1736 por encargo del cabildo, no interviniendo en la obra de la fachada de la Catedral que se acometió en 1740.

La figura más relevante de la segunda mitad del siglo XVIII fue el maestro de arquitectura, carpintería y ensamblaje, Felipe de Ureña. Este artista, cuyo origen se desconoce, debió nacer en la primera década del setecientos y perteneció a un importante taller familiar junto a sus hermanos José, Carlos e Hipólito. Su dilatada y extensa actividad la desarrolló en diversas ciudades novohispanas, constituyendo un modelo de artista transhumante e inquieto, ajeno a sectarismos provincianos. Trabajó para las órdenes religiosas, fundamentalmente para los franciscanos. Sus primeros pasos como artista los realiza en la capital mexicana y sus alrededores. Se ha identificado su autoría en el retablo que la comunidad de gallegos dedica a Santiago en la capilla del Tercer Orden del convento San Francisco de México y los retablos de la sacristía del convento de San Francisco de Toluca, ambas fechadas hacia $1729^{38}$. ¿Podría tratarse Ureña de un artista de origen gallego? El encargo que le hace la comunidad de gallegos, dedicado a Santiago, nos hace pensar en el origen de este artista cuyo apellido es usual en esa zona del Norte de España. Toussaint dice que los retablos siguen los parámetros artísticos churriguerescos si bien más moderados en la ornamentación que los que utiliza el artista español. En 1739, se le encargaron de nuevo una serie de retablos para la capilla del Tercer Orden del convento de San Francisco de México. El primero de ellos está dedicado a la Virgen de los Dolores, trabajando junto a Joseph de Arriaga, maestro dorador; el contrato especifica que se haga con golpes y movimientos suaves para que la obra salga «arreglada a la buena arte» ${ }^{39}$. Dos años más tarde y en la misma capilla, realizará dos retablos colaterales del altar mayor, terminando en 1742 con la obligación de hacer otros dos más para el coro de la misma capilla. En capital, trabajó también para la iglesia del Carmen, donde en 1741 contrató el retablo mayor junto a Francisco Martínez, dorador.

Ureña conoció y admiró la obra de Jerónimo de Balbás en la capital mexicana e incluso tuvo que copiarle en el retablo mayor que realizó para la iglesia del convento franciscano de Texcoco en 1744. En efecto, vemos como en el contrato para levantar este retablo recibe precisas instrucciones de hacerlo teniendo como modelo el retablo principal que se hallaba en la capilla del Tercer Orden del mismo convento, obra de Balbás, «para su mayor acierto y lustre» ${ }^{40}$. La copia de esta obra debió influir en su posterior evolución artística, utilizando el estípite de forma sistemática como principal elemento tectónico en sus incursiones en el campo de la arquitectura. Así se puede apreciar en el templo de la Compañía de Guanajuato, ciudad en la que ejerció como maestro mayor de obras en la década de los cincuenta. Utiliza un modelo de estípite decorado con un círculo en su tercio inferior y figuras geométricas en la unión con el capitel. Esta iglesia junto al Sagrario Metropolitano fueron las primeras en utilizar el estípite en la fachada, implantando este elemento arquitectónico en la zona norteña. Cuando llega a Oaxaca hacia el año 1766, su formación como artista está consolidada, no exisitiendo en esos momentos en la ciudad ningún arquitecto o retablista que pudiera competir con sus conocimientos y experiencia. En aquel año reconoció los terrenos donde se encontraba la iglesia del Patrocinio para dar un dictamen sobre la conveniencia del lugar como futura sede del convento de indias cacicas. Un año más tarde dirigió, junto a Pedro Delgado, la construcción de un puente sobre el río Atoyac que tuvo que ser abandonado por falta de dinero ${ }^{41}$.

La primera gran obra que acomete en Oaxaca fue el convento de los Siete Príncipes donde

\footnotetext{
${ }^{37}$ AGNEO. Protocolo Juan de Zerecedo. Año 1730, 15 de diciembre.

${ }^{38}$ Toussaint, Manuel: Arte Colonial en México. UNAM. Instituto de Investagaciones Estéticas. México, 1990, p. 180.

39 Tovar de Teresa, Guillermo: México Barroco. México, 1981, p. 331.

40 Tovar de Teresa, Guillermo: op. cit., p. 331.

${ }^{41}$ Berlin, Heinrich: «Oaxaca: la iglesia de San Felipe Neri; noticias de artífices» en AEA. Madrid, 1983, p. 65.
} 


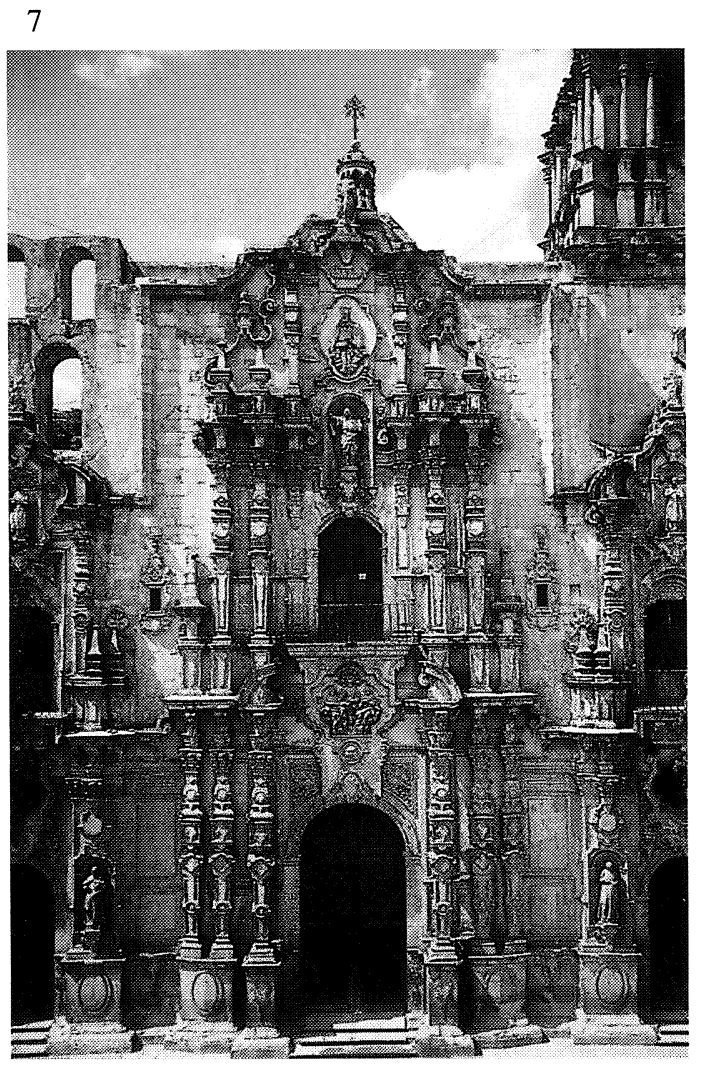

8

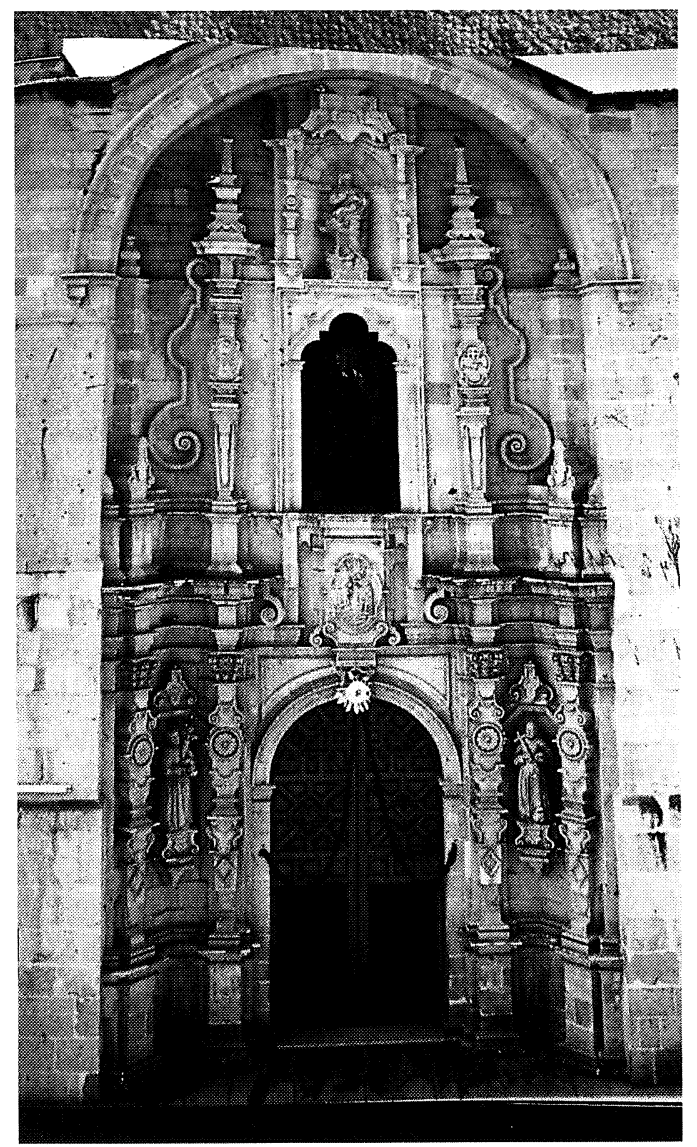

9

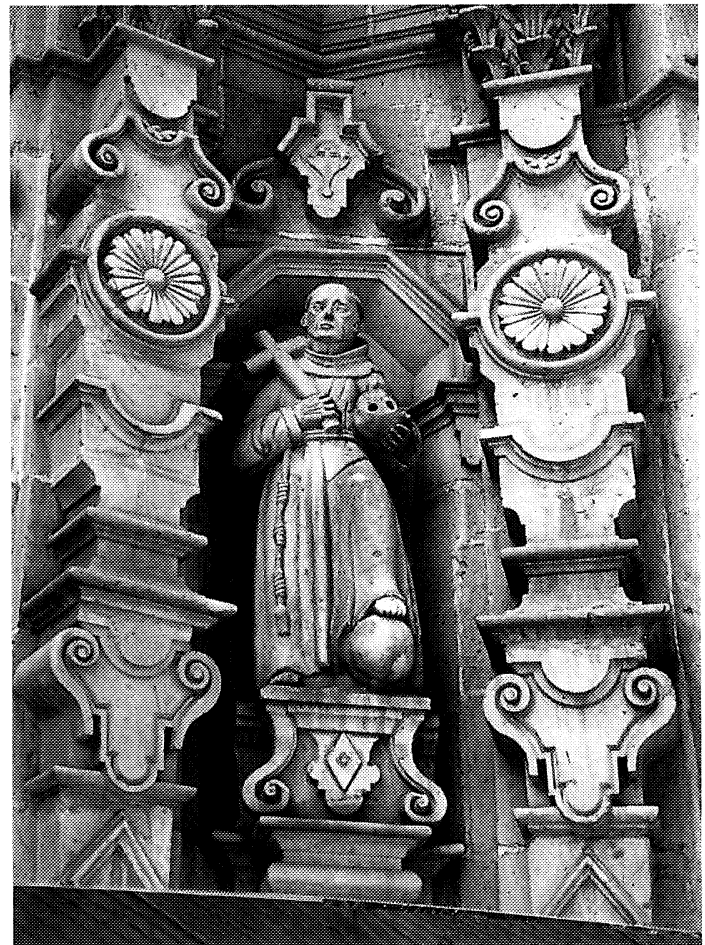

Fig. 7. Guanajuato. Iglesia de la Compañía.

Figs. 8 y 9. Fachada principal y detalle. Oaxaca. Iglesia del convento de San Francisco. 
realiza las trazas para la zona conventual así como la iglesia ${ }^{42}$. En este convento se enfrentó con una gran obra arquitectónica adaptada a unas necesidades determinadas para la comunidad conventual. Tanto la decoración de la entrada al convento como la fachada de la iglesia presentan una sobriedad de elementos muy lejanas a la barroquización que había utilizado Ureña en las tierras norteñas. No nos consta su intervención como retablista pero parece posible que contratase la obra completa, arquitectura y retablos, al no existir otros artistas que trabajasen en ella. Sin embargo, no ocurre lo mismo en el trabajo realizado para la iglesia de San Francisco, realizado entre 1766-1770 y cuya labor fue polifacética. La fachada de la iglesia está inscrita dentro de un gran arco abocinado de suave curvatura cóncava que coincide con la altura de las naves interiores. En este vano se inserta la portada de la iglesia formada por dos cuerpos y remate. El primer cuerpo se organiza mediante una puerta central y dos entrecalles formadas por estípites, donde se albergan sendas imágenes de San Francisco y San Diego de Alcalá sobre peanas. La volada cornisa que separa los cuerpos se rompe para dejar hueco al medallón con el relieve del Bautismo de Cristo. El segundo cuerpo está tratado de diferente manera que el anterior pues presenta un sólo vano central donde se dispone la ventana del coro, flanqueada a su vez por sendos estípites, y una decoración plana de roleos. El ático se dispone mediante una hornacina con estípites que alberga la imagen de la Inmaculada y voluminosos chapiteles que sirven de remate a los estípites del segundo cuerpo. La fachada presenta distintas tipologías de estípites según los cuerpos. En el primer cuerpo aparecen con una decoración geométrica de roleos y rombos en su tercio inferior, mientras que en el central presenta un círculo con una roseta tallada en su interior. En el segundo cuerpo, el estípite es más estrangulado y esbelto presentando un ensanchamiento en su parte central donde se disponen sendos relieves ovalados con escenas franciscanas; su tercio inferior presenta igualmente una decoración geométrica acorde con los tratados manieristas nórdicos. Por último, los estípites del ático son simples pilastras que tienden a una fragmentación mediante círculos, molduras y pirámides invertidas. Toda esta tipología denota la influencia de los tratados manieristas, sobre todo el de Wendel Dietterlin, en lo que respecta a la decoración tendente hacia lo geométrico. Debido a la influencia de estos tratados en la arquitectura y retablística española y mexicana del siglo XVIII —en lo que respecta al empleo del estípite-, algunos autores han llegado a admitir el término «neomanierismo» ${ }^{43}$. La importancia de esta fachada radicó en ser la primera en la que se usó este soporte en el exterior, hecho que sin embargo no iba a traer consecuencias pues no existe otra con semejantes connotaciones; sin embargo, significó el rompimiento de un modelo de fachada característico y tradicional en la ciudad desde finales del siglo XVI y cuyo origen se relaciona con la fachada del convento dominico de Cloixtlauaca de 1576.

La labor de Felipe de Ureña en el convento de San Francisco de Oaxaca no se limitó a la arquitectura sino que intervino en otros campos, presentándosenos como un artista polifacético y culto, con una sólida formación arquitectónica y retablística. Como retablista contrató la hechura de ocho colaterales: el retablo mayor, el de la Purificación, el de San Pedro de Alcántara, dos dedicados a San José, dos dedicados a San Francisco y uno a San Antonio. Lamentablemente no se conservan ninguno de estos retablos ni existe una descripción de los mismos. Su labor como car-

\footnotetext{
${ }^{42}$ Halcón, Fátima: «Arquitectura y retablística novohispana: las obras de Felipe de Ureña en Oaxaca» en $A E A$, n. $^{\circ} 274$. Madrid, 1996 y Castañeda Guzmán, Luis: Templo de los Príncipes y Monasterio de Nuestra Señora de los Ángeles. Instituto Oaxaqueño de las Culturas. Oaxaca, 1993.

${ }^{43}$ Moffitt, Jo $h n$ F.: «El Sagrario Metropolitano, Wendel Dietterlin, and the estípite: observations on mannerism and neoplateresque architectural style in 18th-century mexican ecclesiastical facades» en Boletín de los Seminarios de Arte y Arqueología, t. L, Valladolid, 1984, pp. 325-345; Hellendoorn, Fabienne E.: Influencia del Manierismo Nórdico en la Arquitectura Virreinal Religiosa de México. UNAM. Delf, 1980; Herrera García, Francisco Javier: El retablo sevillano en la primera mitad del siglo XVIII: evolución y difusión del retablo de estípites. Tesis Doctoral inédita. Universidad de Sevilla. Sevilla, febrero, 1998.
} 

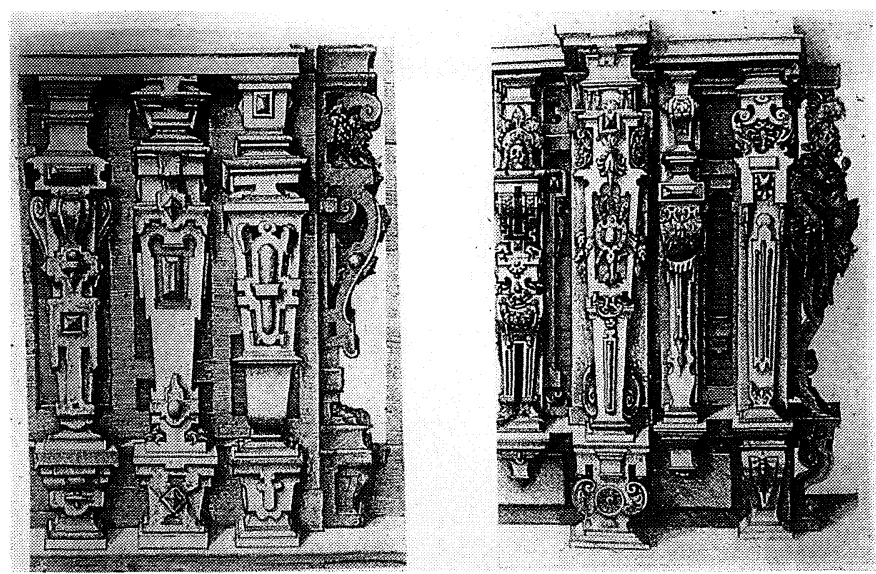

Fig. 10. Wendel Dietterlin. Modelos de estípites Architectura de constitutione symmetria ac proportione quinque columnarum, 1598.

pintero la desarrolló realizando puertas para la sacristía, varandales para el comulgatorio, atriles para los altares nuevos, facistol y tabernáculo para la Virgen que se encontraba sobre la reja del coro. Asimismo actuó como pintor del retablo de la Inmaculada en el cual hizo unos bastidores para que se igualasen a las partes laterales que posteriormente tuvo que pintar de amarillo «fingiendo distramente el dorado que le dio el pintor» ${ }^{44}$.

Además de estas dos grandes obras se conoce la existencia del plano de una casa de la ciudad donde se pensaba edificar un «Colegio de Infantas» en 1769. Ureña hace el proyecto de la adaptación estimando el arreglo en dos mil pesos ${ }^{45}$. Desde el año 1772 se pierden las noticias de este artista en tierras oaxaqueñas, no teniendo constancia de la existencia de más datos por otros lugares de México. Es muy posible que muriese en Oaxaca pues cuando realiza la obra del convento de San Francisco debía estar cercano a los setenta años. Se puede considerar el artista más destacado de la ciudad en la segunda mitad del siglo XVIII. Por su labor arquitectónica podemos deducir que fue conocedor de los tratados de arquitectura, aplicando a sus obra un modelo de estípite de traza quebrada y prismática incorporándole elementos como pequeñas volutas a los lados, triangulillos, rombos y pequeñas cartelas con relieves o rosetas. No llega a sustituir estos elementos geométricos por la rocalla, al menos en su obra arquitectónica, a pesar de utilizarlo en fechas tan tadías como 1772 en que el estípite ya se estaba sustituyendo por otros soportes. Fué un gran innovador en cuanto a la traza arquitectónica como podemos apreciar en la fachada de la iglesia de San Francisco donde introduce un modelo en forma de gruta, de planta cóncava o poligonal, a semejanza de un gran cascarón. En este modelo, copiado de trazas de Balbás, introduce la pilastra estípite como elemento articulador, desempeñando una función a la vez estructural y decorativa.

${ }^{44}$ AGEO. Legajo 19. Exp. 22. Obispado 1766. Citado en Halcón, Fátima: op. cit., p. 181.

45 ACO. Actas de Cabildo 1753-1770. Tomo 6, p. 312.

AGNEO: Archivo General de Notarías del Estado de Oaxaca.

AGEO: Aechivo General del Estado de Oaxaca.

ACO:Archivo Catedral de Oaxaca. 